\title{
SHRINKAGE AND CREEP STRAINS OF CONCRETE EXPOSED TO LOW RELATIVE HUMIDITY AND HIGH TEMPERATURE ENVIRONMENTS
}

\author{
Maya Nastic ${ }^{1}$, Evan C. Bentz ${ }^{2}$, Oh-Sung Kwon ${ }^{2}$, Vassilis Papanikolaou ${ }^{3}$, Julia Tcherner ${ }^{4}$ \\ ${ }^{1}$ Graduate Student, Civil Engineering, University of Toronto, Canada \\ ${ }^{2}$ Associate Professor, Civil Engineering, University of Toronto, Canada \\ ${ }^{3}$ Assistant Professor, Civil Engineering, Aristotle University of Thessaloniki, Greece \\ ${ }^{4}$ Senior Civil Engineer, SNC-Lavalin, Canada
}

\begin{abstract}
Creep and shrinkage of concrete is influenced by many factors including relative humidity and temperature. The combined effect of low relative humidity and high temperature on creep and shrinkage of concrete is uncertain as limited tests have been conducted in this domain. Also unknown is the ability of the fib MC2010 model code in predicting the shrinkage and creep at the environment. This paper presents the preliminary results of experiments conducted in which concrete was cast and exposed to the aforementioned environmental conditions. The shrinkage and creep behaviour of the concrete was observed, and experimental results were compared with predicted values using fib MC2010 model code.
\end{abstract}

\section{INTRODUCTION}

Nuclear power plants constructed in 1970s and 1980s around the world are reaching their design lives and many of them are being refurbished. Most containment buildings of nuclear power plants are reinforced concrete structures which are prestressed in vertical and horizontal directions. Majority of the shrinkage and creep develops in the first ten years after construction. The shrinkage and creep that develop after ten years from construction are not expected to significantly impact the structural performance of containment buildings (Huang et al. 2015, 2017). The study on the effect of aging (i.e. shrinkage, creep, and relaxation) on the structural performance of containment buildings was primarily based on shrinkage and creep prediction equations available in CEB/FIP 90 model code (CEB/FIP 1990).

The shrinkage and creep prediction equations in literature are primarily based on empirical observations from many laboratory tests in controlled environment. Various testing standards are available for shrinkage and creep tests such as RILEM TC 107 (1998), ASTM C512 / C512M-10 (2010), and ASTM C157 / C157M (2014). In such standard testing methods, several testing parameters are specified such as room temperature of $23 \pm 2{ }^{\circ} \mathrm{C}$, relative humidity of $50 \pm 4 \%$, and dimension of specimens (ASTM C157 / C157M 2014). Such standardized tests are useful to understand characteristics of a test specimen in comparison with many other test results subjected to similar condition. In addition, majority of data in the database of concrete shrinkage and creep results (RILEM database) are based on room temperature, medium (50\%) to high (100\%) relative humidity, and volume to surface ratio (V/S) less than $100 \mathrm{~mm}$. Depending on the environmental condition that a reinforced concrete structure is subjected to, however, the shrinkage and creep tests results using the standardized test methods or prediction equations mainly calibrated with such test results may not be applicable.

For example, the temperatures inside nuclear containment structure are higher than typical room temperature and internal relative humidity could be lower than that used for the standard tests. Moreover, V/S ratio of a containment wall is larger than the V/S ratio of standard shrinkage test specimens. After 
thorough review of the test parameters in the RILEM database, the authors found that there is clear lack of shrinkage and creep test results at low relative humidity and high temperature environment.

This paper presents a research in-progress on shrinkage and creep of concrete elements subjected to low relative humidity and high temperature. In addition, to understand the shrinkage behaviour of concrete with large volume to surface ratio, specimens with one-dimensional dehydration boundary condition are tested. Testing configurations, control of environment, instrumentation and measurement systems are briefly discussed, which is followed by summary of preliminary findings.

\section{EXPERIMENTAL PROGRAM}

The main objective of the experimental program is to investigate the shrinkage and creep behaviour of concrete specimens subjected to low relative humidity and high temperature environmental conditions. Creep test has been carried out in a low relative humidity and high temperature environmental chamber developed at the University of Toronto. Shrinkage specimens have been tested in four different environmental conditions as summarized in Table 1.

Table 1: Summary of Test Specimens

\begin{tabular}{|c|c|c|c|c|}
\hline \multicolumn{2}{|c|}{ Test } & Relative humidity & Temperature & Specimens \\
\hline \multirow{4}{*}{ Shrinkage } & \multirow{2}{*}{ Env. A } & $10 \%$ & $40^{\circ} \mathrm{C}$ & $\begin{array}{c}\text { G1, G2, } \\
\text { F3, F6, F11 }\end{array}$ \\
\cline { 2 - 5 } & Env. B & $10 \%$ & Ambient temperature & $\begin{array}{c}\text { G3, G4, } \\
\text { F2, F10, F12 }\end{array}$ \\
\cline { 2 - 5 } & Env. C & \multicolumn{2}{|c|}{ Ambient environment } & $\begin{array}{c}\text { G5, } \\
\text { F4, F8, F9 }\end{array}$ \\
\cline { 2 - 5 } & Env. D & $100 \%$ & Ambient temperature & F1, F5, F7 \\
\hline \multicolumn{2}{|c|}{ Creep } & $10 \%$ & $40^{\circ} \mathrm{C}$ & C1, C2, C3, C4, C5 \\
\hline
\end{tabular}

\section{Shrinkage Tests}

\section{Specimens}

Shrinkage tests were carried out using two types of specimens: free shrinkage specimens and gradient specimens. The free shrinkage specimens had dimensions of $76.2 \times 76.2 \times 285 \mathrm{~mm}$. A total of 12 free shrinkage specimens were used. Five rectangular test specimens (gradient specimens) were also created in order to determine the spatial and temporal variation in shrinkage, internal relative humidity, and temperature in a concrete specimen due to one-dimensional diffusion and environmental conditions. The specimens had dimensions of $125 \times 125 \times 550 \mathrm{~mm}^{3}$. Except one face of the specimen, all other faces were coated with epoxy such that moisture can be diffused only in one direction. These specimens are referred to as "gradient" specimens as they allow only one-dimensional diffusion and gradient of internal relative humidity and shrinkage strain profile.

\section{Environment Control}

Environmental chambers were built at the University of Toronto with two large tote bins, heat source, temperature controller, and desiccant as illustrated in Figure 1. The first environment had a relative humidity of approximately $10-15 \%$ and a temperature of $40^{\circ} \mathrm{C}$ (Env. A. in Table 1). The second environment had a relative humidity of approximately 10-15\% and was kept at room temperature (Env. B). In order to maintain an environment in which the relative humidity remained at approximately 10$15 \%$, silica gel was used as a desiccant. The desiccant was placed in trays inside the tote bins. Generally, $304 \mathrm{~g}$ of desiccant was used in the Env. B and $114 \mathrm{~g}$ of desiccant was used in the Env. A at any given time. A fan was installed in each chamber to allow circulation of air in the chamber. The saturated desiccant was replaced with desiccant dehydrated in an oven. To achieve a temperature of $40^{\circ} \mathrm{C}$, a heating 
source with a fan and temperature controller (parts from an egg incubator) was used. To prevent the heat from escaping from the environmental chamber via convection, a chamber constructed of foam board surrounded the environmental chamber on all sides except for the bottom face. Part way through the conducted experiments ( 194 days), the heat source was replaced with a heat cable and a thermostat which are identical to those used in the creep chamber.

\section{Instrumentation and Measurement}

A comparator was used to measure the change in length of the free shrinkage specimens (F1 F12). In order to use the comparator, it was first zeroed using an invar rod. The specimen was then placed, in the same orientation for every measurement in the comparator. The reading in the comparator designated the difference in length of the specimen based on an assumed length of $285 \mathrm{~mm}$ (i.e. if the specimen was expected to be $285 \mathrm{~mm}$ long but in reality measured $290 \mathrm{~mm}$ in length, the comparator would read +5.000 $\mathrm{mm})$. The comparator had an accuracy of $0.001 \mathrm{~mm}$.

A Pfender gauge was used to take longitudinal and transverse strain measurements of gradient specimens (G1 G5). The gauge is capable of measuring the length between two targets with an accuracy of $0.001 \mathrm{~mm}$. Five internal strain gauges with a gauge length of $5 \mathrm{~mm}$, and 2 or 3 surface strain gauges with a gauge length of $60 \mathrm{~mm}$ were used to measure shrinkage strains of the gradient specimen. The Vishay Instrument Strain Indicator was used to monitor these strains.

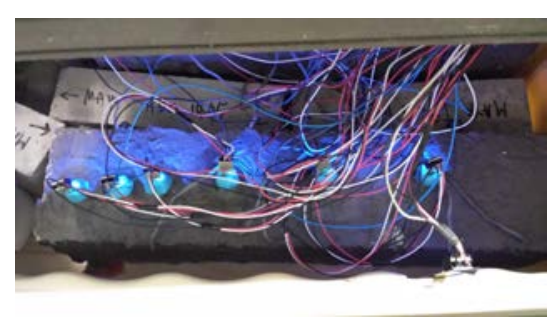

Gradient specimen with concRHT sensors

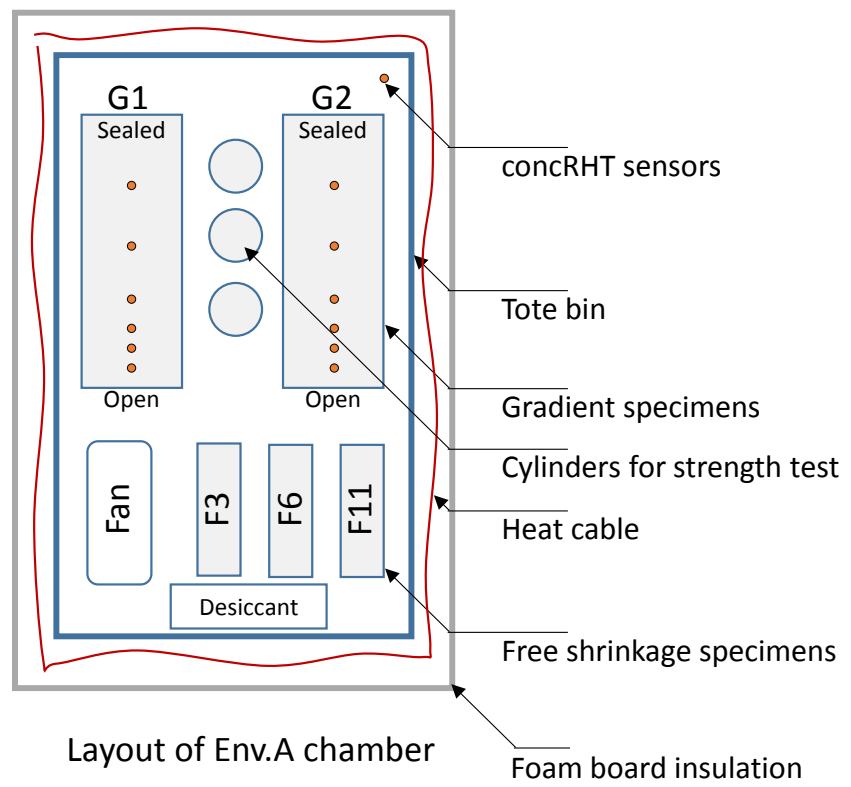

Foam board insulation

Figure 1. Gradient specimen and layout of environmental chamber (Env.A)

In-house made sensor probes, termed as concRHT probes shown in Figure 2, were inserted in the gradient specimens $(\mathrm{G} 1 \sim \mathrm{G} 3)$ through holes to measure the relative humidity and temperature along the length of the specimens. Excitation voltage signals were generated from a general purpose analog input/output system (LabJack), which also includes A/D converters for data logging. The readings from the sensors were converted to temperature $\left({ }^{\circ} \mathrm{C}\right)$ or relative humidity (\%) values. The typical accuracy of the sensor was $\pm 0.2^{\circ} \mathrm{C}$ and $\pm 2.0 \%$ for ambient environment. At high/low temperature $\left(\mathrm{T}>60^{\circ} \mathrm{C}\right.$ or $\mathrm{T}<10^{\circ} \mathrm{C}$ ) or relative humidity $\left(\mathrm{RH}>80 \%\right.$ or $\mathrm{RH}<20 \%$ ) ranges, the accuracy gradually decreases to $\pm 0.7^{\circ} \mathrm{C}$ and $\pm 3 \%$. It is expected however that once the sensor is exposed to relative humidities less than $80 \%$, recalibration will slowly occur and there will no longer be an offset in relative humidity (Sensirion 2014). The concRHT probes was placed in each environment (Env. A, Env. B, and Env. C) to record the relative humidity and temperature at all times. 


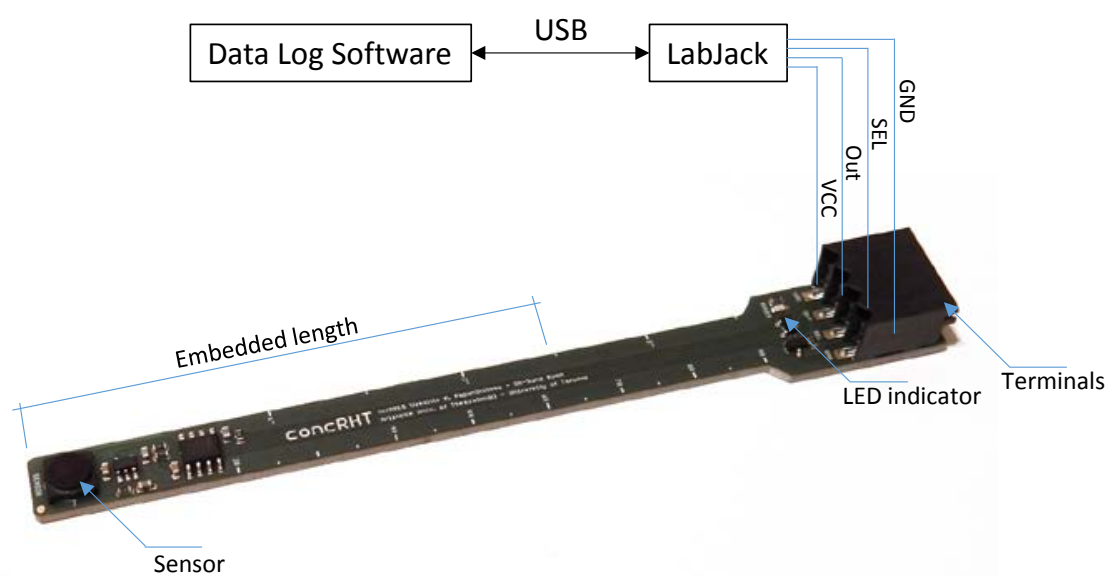

Figure 2. Embedded concRHT probes (relative humidity and temperature sensors)

\section{Creep Tests}

\section{Specimens}

The creep specimens consisted of five $152 \mathrm{~mm}$ by $305 \mathrm{~mm}$ (6” by 12”) cylinders. They were stacked one on top of the other inside the creep frame. At the top and bottom of the stack, a half cylinder with dimensions $152 \mathrm{~mm}$ by $152 \mathrm{~mm}$ (6" by 6") was included to help distribute the applied load evenly to the specimens.

\section{Loading Frame}

The creep frame consisted of three steel plates (17” by 17” by 2") held in place via four partially threaded steel bars with 1.75 " in diameter. The plates were secured at specific heights along the partially threaded steel bars using tightened nuts. Specimens, a load cell, and a hydraulic cylinder were placed between the middle and bottom plates within the cage created by the partially threaded steel bars.

A hydraulic cylinder and disc springs were used to apply a constant load of $91 \mathrm{kN}$ to the creep specimens, which is equivalent to $5 \mathrm{MPa}$. A small square steel plate was placed below the hydraulic cylinder to ensure an even distribution of load to the specimens. The hydraulic cylinder and steel plate were placed on top of the stack of creep specimens. As the oil from the air/hydraulic pump was pumped into the hydraulic cylinder, the piston moved upward thus pushing against the underside of the middle plate. This in turn applied a load to the creep specimens as the movement of the middle plate was restricted by the disc springs. The disc springs were used in order to reduce the overall stiffness of the system which reduces fluctuation of forces. If the springs were not present, the application of the force to the specimens would be extremely abrupt, difficult to control, and likely would have resulted in poorer results.

\section{Environment Control}

Foam board was used to create a chamber surrounding the creep frame. The chamber was approximately flush with the floor (some air gaps were present) and extended up for 84". A fan was placed at the bottom of the chamber and angled upward to circulate the air within the chamber. A dehumidifier was used to remove moisture from the environment in order to maintain a relative humidity of approximately $10-15 \%$. The dehumidifier was placed at the foot of the creep frame. In addition, silica gel was used as a desiccant. The desiccant was placed at the bottom of the chamber, beside the dehumidifier and the fan. Typically, either $532 \mathrm{~g}$ or $0 \mathrm{~g}$ of desiccant was used at any given time. A heat cable and a temperature controller were used to heat the environment to $40^{\circ} \mathrm{C}$. The heat cable was wrapped around the partially threaded steel bars. The sensor of the thermostat was placed inside the chamber at approximately one third the height of the chamber. 


\section{Instrumentation and Measurement}

Applied load was controlled using an air/hydraulic pump which maintains constant oil pressure in the hydraulic jack. To directly measure the applied force to the specimen, a load cell was used at the top of the specimen stack. The applied force was logged at a routine interval. To measure the creep strains on specimens, three strain gauges at were instrumented on the surface of each specimens (C1 through C5). To monitor the temperature and humidity of the environmental chamber, the concRHT sensor probes were installed in the chamber.

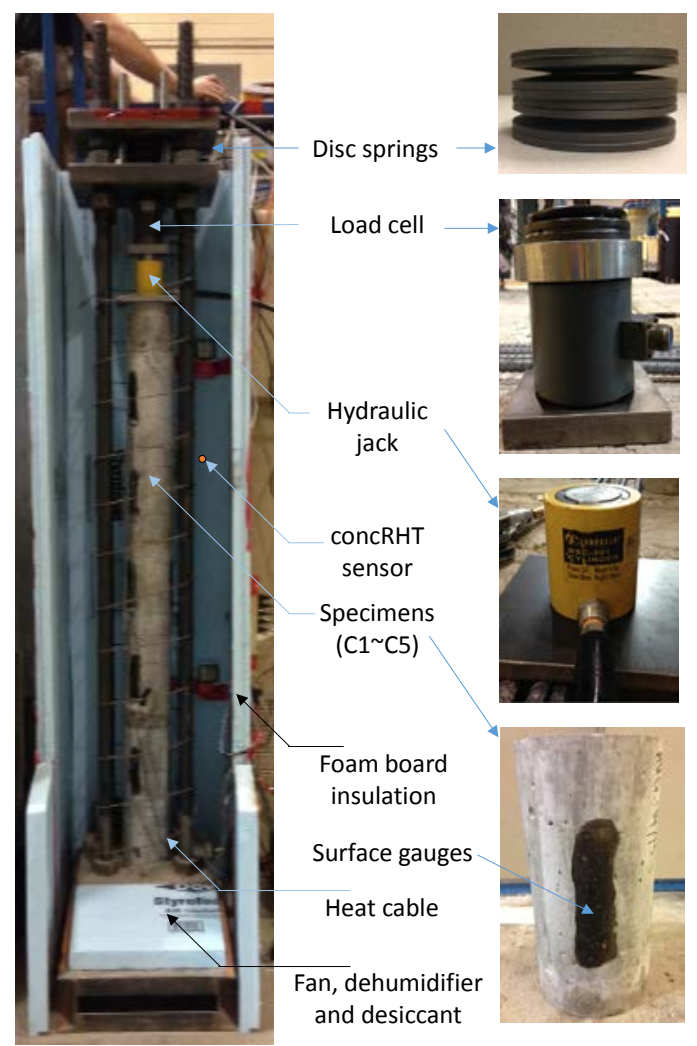

Figure 3. Configuration of creep testing frame

\section{Testing Procedure}

The specimens were cast in plastic cylindrical molds. After approximately two to three hours after casting the specimens, a wet burlap layer and plastic tarp were placed on the exposed concrete surfaces to prevent excessive drying while curing began. After one day, the specimens were removed from the molds and placed inside a fog room where the relative humidity is maintained at a constant $100 \%$. After 29.75 days in the fog room, the specimens were removed from the fog room and placed in ambient temperature in order to allow for the surface of the specimens to dry and to attach all required instrumentation before placement into the creep setup. Before setting up the specimens in the creep frame, the environment within the chamber were stabilized at the desired temperature and relative humidity. However, upon opening the foam board to place the specimens in the setup, temperature control was lost and ambient environment conditions were established in the creep chamber at the time of loading of the specimens.

The creep specimens were stacked inside the creep frame such that a half cylinder was at the bottom of the stack, followed by specimens C1, C2, C3, C4, C5, and finally a half cylinder at the top of the stack. Once stacked, the load was applied to the creep specimens. The age of the concrete at this time 
was 35 days. For the first 2.5 weeks since the surface strain gauges were glued to the creep specimens, strain measurements were taken daily. For the following three, strain measurements were taken three times per week. For the next 6 months, measurements were taken 1-2 times per week.

\section{Concrete Mix Design}

Various trial mixes were tested to replicate the shrinkage and creep behaviour of 40-year-old concrete. It was desired to use Type III cement (high early strength cement) in order to replicate the behaviour. When concrete is very mature, the hydration process is complete and the concrete is no longer gaining significant strength with time. In addition, the creep and shrinkage behaviour is expected to have reached a maximum value. In using high early strength cement, the concrete will complete hydration relatively quickly and, as a result, the characteristics and behaviour of very mature concrete could be achieved in a matter of weeks. However, the 28-day strength of the concrete obtained using high early cement was far greater than $34.5 \mathrm{MPa}$ (the desired compressive strength), regardless of the cement mix. This was expected since the strength of concrete depends on the water to cement ratio as opposed to the cement content, as Abrams' Law and Feret state (Neville and Brooks 2010) and as was observed in the 28-day strength results of the trial mixes. Type I (general purpose cement) was used for the specimens. The following table describes the proportions of the various components of the concrete mix used in the experiments. The mix design was selected because it contained a distribution of fine and coarse aggregates (the fine to coarse aggregate ratio was 1:1), which allowed for a workable mix and no honeycombing resulted. The maximum size of aggregates used was $19 \mathrm{~mm}$.

Table 1: Concrete Mix Design for Specimens

\begin{tabular}{|l|c|}
\hline Cement $\left(\mathrm{kg} / \mathrm{m}^{3}\right)$ & 474 \\
\hline Fine Aggregate $\left(\mathrm{kg} / \mathrm{m}^{3}\right)$ & 807 \\
\hline Coarse Aggregate $\left(\mathrm{kg} / \mathrm{m}^{3}\right)$ & 807 \\
\hline Water $\left(\mathrm{kg} / \mathrm{m}^{3}\right)$ & 186.6 \\
\hline W/C & 0.39 \\
\hline
\end{tabular}

\section{EXPERIMENTAL RESULTS AND COMPARISONS WITH PREDICTIONS}

The following discussion presents measurements up to approximately 110 days of concrete age. The results are compared with the prediction using FIB MC2010 assuming 42.5N strength class of the cement. Actual strength class of cement needs to be measured from experiments. Thus the comparison of the prediction with the experiemntal result is tentative. More general conclusion will be drawn after identifying the strength class of the cement.

\section{Temperature and humidity history}

Figures 4 and 5 present measured temperature and relative humidity history of Env. A for shrinkage specimens and the creep frame. The concRHT sensor probe began recording the environment inside the Env. A at a concrete age of 34 days. The various specimens were placed in the Env. A at a concrete age of 35 days. However, it was only at approximately 36 days that the environment began to approach the desired conditions. While not presented in this paper, the temperature of Env. B was maintained closed to $22.5^{\circ} \mathrm{C}$ with humidity of $12.4 \%$. The temperature profile of Env. C was similar the temperature profiel of Env. B. However, because humidity was not controlled tightly in the indoor environment, the relative humidity fluctuated from $60 \sim 70 \%$ to $20 \sim 30 \%$ largely depending on the outdoor temperature (i.e. in the winter, the relative humidiy decreased.). The relative humidty of Env. D (fog room) is assumed to be $100 \%$ at a temperature of $25^{\circ} \mathrm{C}$. 

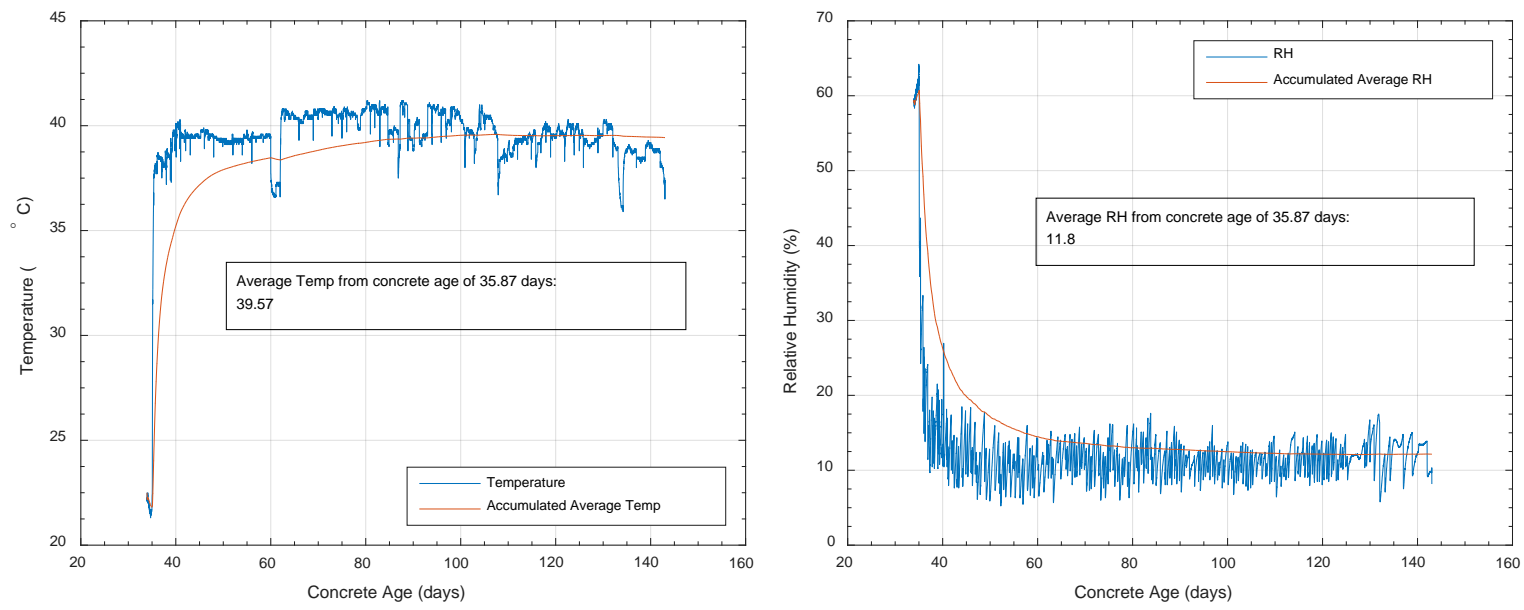

Figure 4. Recorded temperature and relative humidity history of Env. A
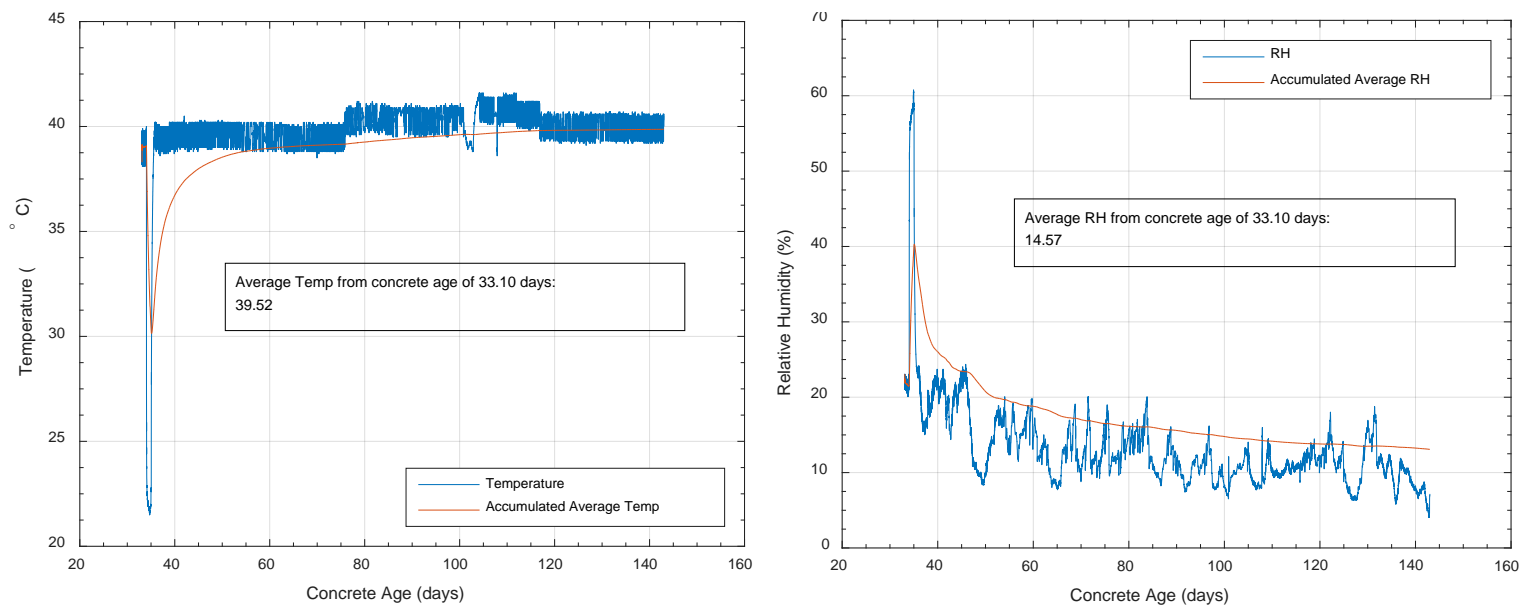

Figure 5. Recorded temperature and relative humidity history of creep frame

The concRHT sensor began recording the environment inside the creep chamber at a concrete age of 33 days. At this point in time, the environment inside the creep chamber had almost reached the desired conditions. The creep specimens were exposed to the creep chamber environment at a concrete age of 35 days. However, when the foam board was removed in order to insert the creep specimens, the environment proceeded to change from the desired conditions - the temperature dropped and the relative humidity increased. It was only at a concrete age of 36 days that the environment inside the creep chamber began to once again reach the desired conditions. The relative humidity and the temperature inside the creep chamber were $23.1 \%$ and $40.0^{\circ} \mathrm{C}$ respectively at this time. 


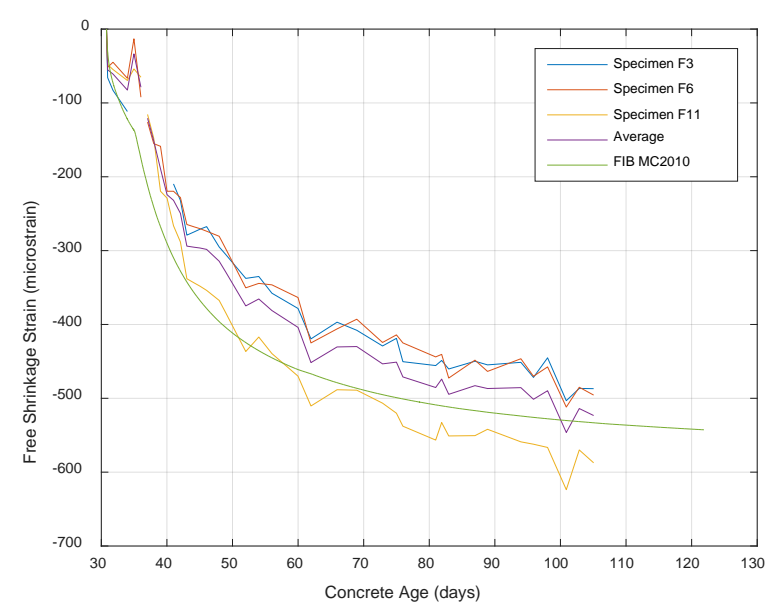

(a) Measured and predicted shrinkage in Env. A

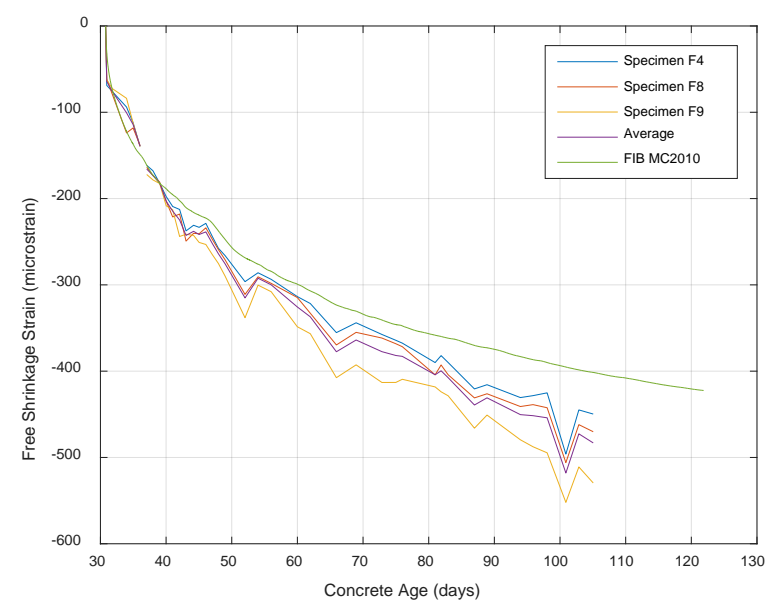

(c) Measured and predicted shrinkage in Env. C

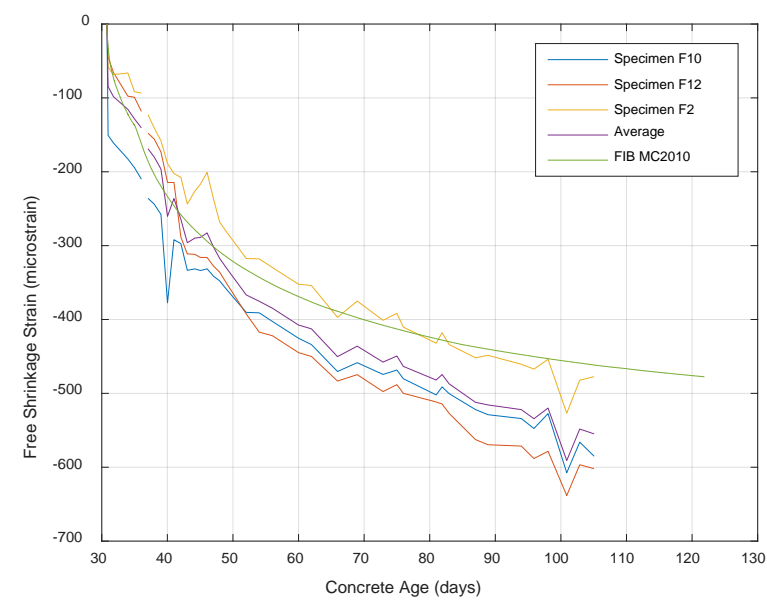

(b) Measured and predicted shrinkage in Env. B

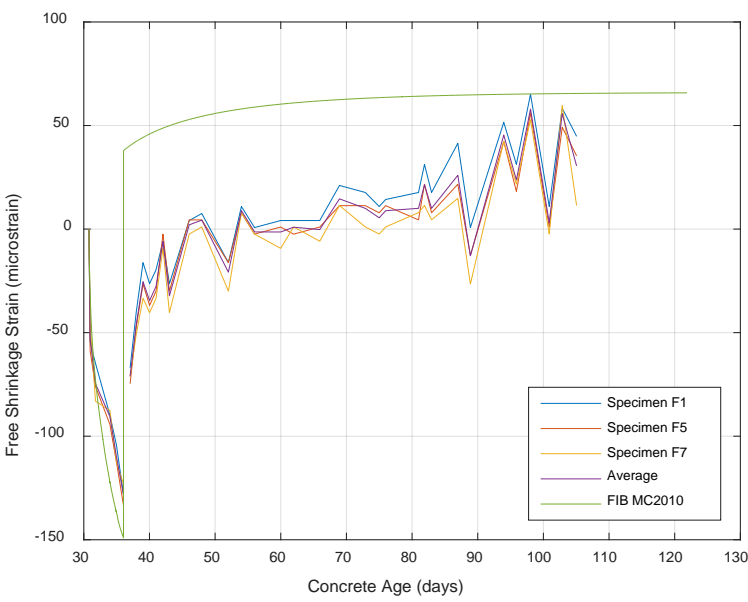

(d) Measured and predicted shrinkage in Env. D

Figure 6. Measured strains from free shrinkage specimens

\section{Measured shrinkage and comparison with model code}

The measured data from gradient specimens is still being analysed. The results from free shrinkage specimens and creep specimens measured up to approximately 110 days are presented in this paper. The length change of the free shrinkage specimens was measured with comparator, which included deformation due to temperature. The total strain experienced by a free shrinkage specimen at time $t$ was calculated as the change in length at time $t$ divided by the original length of the specimen (length at time $t$ $=0$ ). This total strain includes thermal strain and shrinkage strain. The change in length of a free shrinkage specimen at time $t$ was taken as the difference between the measured length indicated by the comparator at time $t$ and the measured length indicated by the comparator at time $t=0$. The thermal strains that the free shrinkage specimens experienced were calculated using a coefficient of thermal expansion that was taken as $6 \times 10^{-6} /{ }^{\circ} \mathrm{C}$ (Collins and Mitchell 1991). However, the actual thermal expansion coefficient of shrinkage specimens needs to be measured through experiment. The corrected values will be presented in future publications.

Figure 6 depicts comparisons between the predicted shrinkage strain and the experimental shrinkage strain experienced by the free shrinkage specimens in their various environments. The predicted shrinkage strain was obtained using the fib MC2010 model for shrinkage using $42.5 \mathrm{~N}$ strength class 
cement, where the limits on relative humidity and age of concrete at start of drying were ignored. The relative humidity and the temperature input to the fib MC2010 shrinkage model were taken as the average accumulated relative humidity and average accumulated temperature as recorded by the concRHT sensors.

It can be seen that for free shrinkage specimens in the Env. C (Fig. 6 (c)) and the Env. B (Fig. 6(b)), the fib MC2010 slightly underestimates the shrinkage. For free shrinkage specimens in the Env. A (Fig. 6(a)), the fib MC2010 seems to accurately predict the shrinkage over the period of 110 days. Overall, regardless of the environment, it can be concluded that the fib MC2010 model for shrinkage can predict the shrinkage strain fairly accurately. Furthermore, based on these results, it is evident that the fib MC2010 model for shrinkage can be used for relative humidities that are outside the set limits. This conclusion however needs to be revisited after properly correcting thermal strain component by measuring thermal expansion coefficient, and by using experimentally identified strength class of cement in the fib MC2010 prediction model.

\section{Measured creep and comparison with model code}

In order to determine the creep strain experienced by the creep specimens, the average shrinkage strain experienced by the free shrinkage specimens in the Env. A was subtracted from the average creep and shrinkage strain experienced by the creep specimens. The shrinkage strains experienced by the creep specimens were not directly measured, therefore this approximation was made. As the first data point of the average creep and shrinkage strain experienced by a creep specimen has already been zeroed for shrinkage strain, there was no need to subtract the average shrinkage strain experienced by the free shrinkage specimens in the Env. A again for this data point. Therefore, the subtraction was only necessary starting from the second data point of the average creep and shrinkage strain of the creep specimens.

The predicted creep strain was obtained using the fib MC2010 model for creep, where the limits on humidity and age of concrete at start of drying were ignored. The relative humidity and the temperature input to the fib MC2010 creep model were taken as the average accumulated relative humidity and average accumulated temperature as recorded by the concRHT sensor. The load that was inputted to the fib MC2010 creep model was the average load in Figure 7. The transient strain component estimated by the fib MC2010 model was included, the predicted creep strain was zeroed, and the elastic strain was neglected in order to properly match the experimental creep strain.
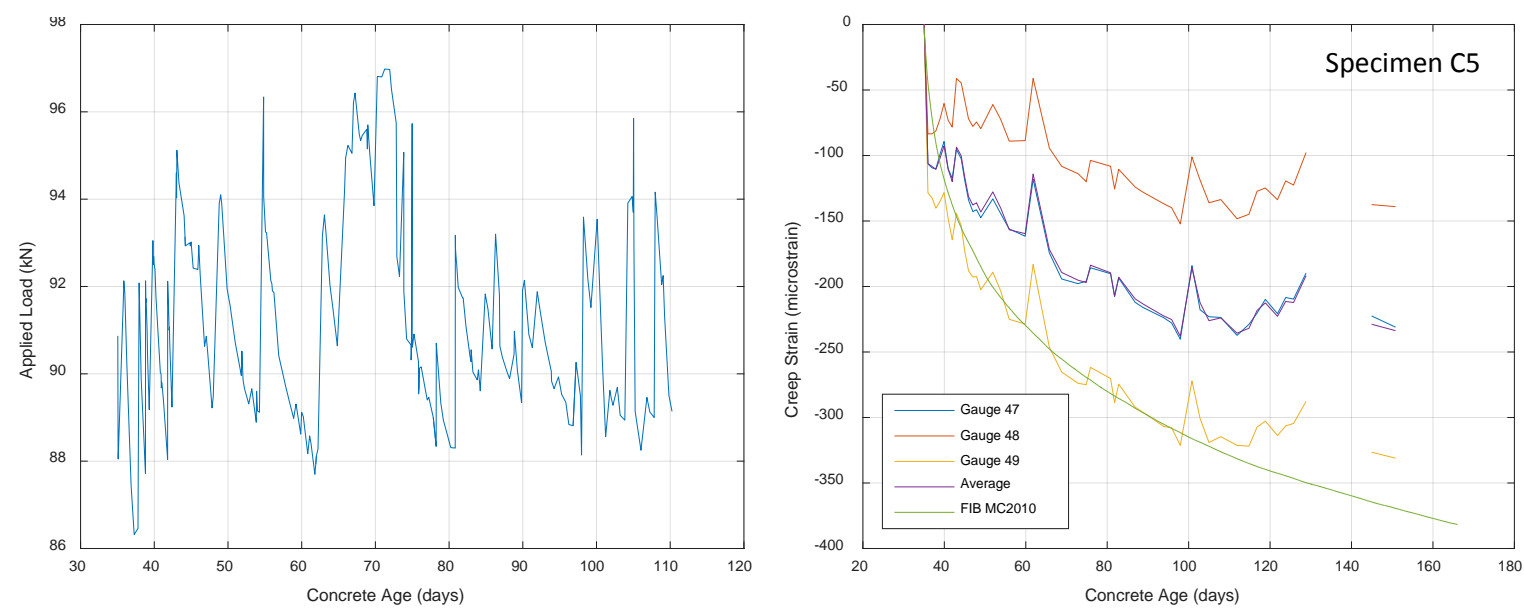

Figure 7. Applied loading history and comparison of measured and predicted creep strains

The fib MC2010 model consistently overestimates somewhat the creep strain for all five specimens from a concrete age of 40 days and onward. Overall, the fib MC2010 model for 
creep/compliance can provide a conservative estimate of the creep strains. The results also show that the fib MC2010 model for creep/compliance can be used with relative humidities that are outside the set limits.

\section{CONCLUSIONS}

The following preliminary conclusions can be drawn based on the results of the conducted experiments. Based on the measurements from free shrinkage specimens, the fib MC2010 model for shrinkage:

- $\quad$ slightly underestimated the shrinkage strains of specimens stored in ambient conditions (Env. C)

- slightly underestimated the shrinkage strain of specimens stored in room temperature and low relative humidity (Env. B)

- appears to have accurately predicted the shrinkage strains of specimens stored in low relative humidities and at high temperatures (Env. A)

- overestimated the swelling of specimens stored at $100 \%$ relative humidity and room temperature (Env. D)

The fib MC2010 model for creep conservatively predicted the creep strains of specimens stored at low relative humidities $(<20 \%)$ and high temperatures $\left(\sim 40^{\circ} \mathrm{C}\right)$

The above conclusions are based on assumptions on thermal expansion coefficient of $6 \times 10^{-6}$ and $42.5 \mathrm{~N}$ strength class cement. To draw general conclusions, these two parameters need to be experimentally validated and the shrinkage and creep strains need to be observed for a longer term. The experiments are ongoing and the updated results will be presented in future publications.

\section{ACKNOWLEDGEMENT}

This study is sponsored by CANDU Owners Group, Inc and Natural Sciences and Engineering Research Council of Canada through Collaborative Research Development program.

\section{REFERENCES}

ASTM C157 / C157M. (2014). Standard Test Method for Length Change of Hardened Hydraulic-Cement Mortar and Concrete. ASTM International, West Conshohocken.

ASTM C512 / C512M-10. (2010). Standard Test Method for Creep of Concrete in Compression. ASTM International, West Conshohocken, PA.

CEB/FIP. (1990). CEB-FIP Model Code 1990. Comite Euro-International du Beton.

Collins, M. P., and Mitchell, D. (1991). Prestressed Concrete Structures. Prentice-Hall.

Huang, X., Kwon, O., Bentz, E., and Tcherner, J. (2015). "Effects of Time-Dependent Parameters on the Performance of a Concrete Containment Structure.” SMiRT 23, Manchester, UK.

Huang, X., Kwon, O.-S., Bentz, E., and Tcherner, J. (2017). "Evaluation of CANDU NPP containment structure subjected to aging and internal pressure increase.” Nuclear Engineering and Design, 314, 82-92.

Neville, A. M., and Brooks, J. J. (2010). Properties of Concrete. Longman Scientific \& Technical, Harlow, Essex.

RILEM Technical Committee TC 107. (1998). "Measurement of time-dependent strains of concrete. TC 107: Creep and Shrinkage Prediction Models: Principles of Their Formation.” Materials and Structures1, 31, 507-512.

Sensirion. (2014). "Datasheet SHT21S Humidity and Temperature Sensor IC." $<$ https://www.sensirion.com/fileadmin/user_upload/customers/sensirion/Dokumente/2_Humidity_S ensors/Sensirion_Humidity_Sensors_SHT21S_Datasheet_V4.pdf> (Mar. 26, 2017). 